\title{
Ecological aspects of economical development: issues of forecast greenhouse gas emissions in road transport in Europe and regions of Russia
}

\author{
Leontiy Eder ${ }^{1,2}$, Irina Filimonova ${ }^{1,2}$, Vasily Nemov $^{1,2}$, Anna Komarova ${ }^{1}$, and Kirill Sablin ${ }^{2}$ \\ ${ }^{1}$ Novosibirsk State University, Russia \\ ${ }^{2}$ Federal Research Center of Coal and Coal Chemistry SB RAS, Russia
}

\begin{abstract}
Environmental aspects are an essential part of economic development. Improvement of the environmental situation can have a significant impact on the pace and structure of economic development. For environmental component, it is important to analyze the current state and predict greenhouse gas emissions. The development of methodological approaches in this area will allow for more detailed forecasting of the situation. In order to reduce the emission of greenhouse gases, European countries have set targets for efficiency of energy consumption and widespread use of renewable energy sources, which they have achieved and become world leaders in using them. By 2020, the goal is set for energy consumption to be at least $20 \%$ from renewable sources. According to the forecast on average, in 2040 the share of oil products in the structure of fuel consumption in road transport in Europe will be reduced to $80 \%$. Nevertheless, in the countries of Europe, various trends in the field of greenhouse gas emissions are expected. Most countries have a high potential for reducing greenhouse gas emissions from fuel combustion on road vehicles. In Russia, emissions from vehicles are projected to reduce by $8 \%$ by 2040 .
\end{abstract}

\section{Introduction}

Analysis of the current situation and forecasting in the energy sector is a key component in the formation of long-term policies for sustainable development of the economy $[1,2]$. An important aspect is the relationship between the economy and its major industries, energy and environment. Transport is one of the largest and strategically important industries. Given that transport is the main consumer of petroleum products, the transport sector accounts for about $30 \%$ of total energy consumption.

In order to reduce the emission of greenhouse gases, European countries have set targets for efficiency of energy consumption and widespread use of renewable energy sources, which they have achieved and become world leaders in using them.

By 2020, the goal is set for energy consumption to be at least $20 \%$ from renewable sources (Directive $2009 / 28 / E C$ ) and at least $27 \%$ by 2030 (2030 Energy Strategy). Forecast of energy consumption by vehicles in Europe and in Russia and its regions is needed to determine the long-term guidelines for the development of energy markets, development of transport infrastructure, petrochemical and related industries, ecology and environment.

At the same time, the rapid growth of greenhouse gas emissions in transport makes it the largest source of emissions, and the high growth rates of emissions over the past five years brought it to the pre-crisis level of 2008.

Motor transport is the largest and most variable source of pollution relative to other modes of transport. On one hand the volume of emissions is affected by the growth of the absolute number of vehicles, on the other hand, the ecological characteristics of traditional engines are improving, and hybrid technologies and electric motors with zero emission of carbon dioxide are being rapidly implemented.

The object of the study is the motor transport of the countries of Europe and regions of Russia. The subject of the study is methodological approaches to forecasting of the energy consumption by road transport and greenhouse gas emissions.

The purpose of the study is to establish long-term trends and forecasts for the energy consumption by road transport and estimation of greenhouse gas emissions.

The objectives of the study include: 1) identification of sustainable trends in the dynamics of motorization and structures of energy use in the road transport; 2) development of methodological approaches to the forecasting of the energy consumption by road transport; and 3) estimation of greenhouse gas emissions by fuel combustion in cars.

Scientific novelty of research consists of:

- proposed directions for improvement of the methodological approach to forecasting energy consumption in the transport sector, taking into account 
specific characteristics of the countries and regions and prerequisites for stable trends in improving the efficiency of energy consumption by road transport;

- multi-factor model built on the basis of established and systematized indicators, allowing to calculate the transport saturation level for the economy in the medium and long term perspective, depending on a number of selected factors;

- estimation of the greenhouse gas emissions in European countries and regions of Russia for the period up to 2040 on the basis of the forecasted number of vehicles, energy consumption and energy structure.

The paper is organized into following sections: (1) an introduction to the study; (2) a literature review; (3) the data and methodology; (4) results and discussion; and (5) conclusions.

\section{Literature review}

Both global and Russia's economy show persistent trends that differently influence energy consumption and structure of the road transport sector, including: 1) increased number of vehicles; 2) higher engine efficiency; 3) appreciable shifts in the structure of energy consumption.

In order to determine the long-term targets of energy consumption in the transport sector of Russia it is necessary to consider global trends, especially in the EU and to determine the possibilities of their application with the specificity of Russian regions taken into account.

\subsection{Vehicle quantity dynamics}

In most developed countries, the optimal vehicle saturation level per 1,000 population has been achieved. Given that energy consumption dynamics in the transport sector is most affected by increasing engine efficiency, this results in gradual reduction of energy consumption [3]. However, in most countries with developing economies, the current level of vehicle ownership is far from saturation, while the transport fleet growth rate is consistently high. As a result, despite the developing energy-saving technologies, energy consumption in transport sector is generally increasing $[4,5]$.

The relationship between the number of cars per capita and GDP is not linear. The specific number of vehicles is growing relatively slow at low levels of this indicator, which is followed by about two-fold increase in an average level (from $\$ 3,000$ to $\$ 13,000$ per capita) [6]. With further increase in GDP per capita, there is a slowdown in growth in the number of vehicles as long as the number of cars per capita reaches a certain level, which is interpreted to be vehicle saturation level in the economy [7]. This dependence is shown in Figure 1. Notably, we used the data from countries with different income levels during the period of 1991-2013.

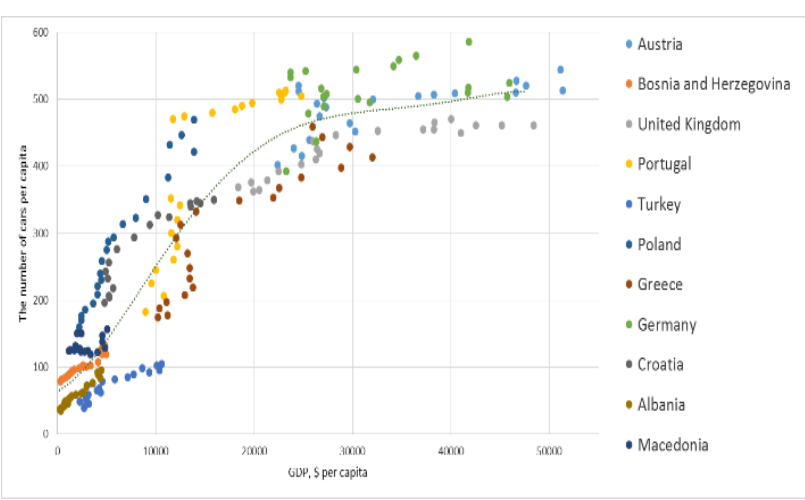

Fig 1. The relationship between number of vehicles and GDP per capita in some countries, according 1991-2013. Source: European Commission: Eurostat; World

As a result, the relationship between the number of vehicles and the GDP per capita can be represented by an S-shaped curve. There are a lot of different functional forms that can describe such process, for example, logistics, and logistics logarithmic, normal storage. Gompertz function shows the most accurate description of the level variation that is connected with motorization of population depending on the level of GDP. The function parameters allow changing the intensity of growth at different stages and the time of reaching the level of vehicle saturation, depending on the level of GDP per capita.

\subsection{Energy consumption per unit of vehicle}

The second important factor is to identify the laws of energy consumption dynamics per unit of a motor vehicle or specific energy consumption [8]. The research made by the authors has shown that the dynamic trend models allow a high degree of certainty to describe the patterns of change in the share of energy consumption in developed countries, showing relatively long downward trend of this indicator (over 20 years). At this, specific energy consumption per unit of GDP is described by an exponential dependence [9]. This means that with time, the growth of energy intensity tends to be decreasing evenly.

The duration of the energy consumption reduction dynamics in the transport sector is not as long as in economy on the whole. As a result, in addition to the exponential, energy consumption in the transport sector can be described by a number of other trends, in particular by a linear trend (Fig. 2). This is because the nonlinearity can be documented for a sufficiently long period of time. Therefore, when predicting specific energy consumption in the transport sector, the dynamics of energy consumption by a vehicle unit is assumed to be described by the same laws as changes in the energy intensity for the whole economy. The basic principles of open economy and participation in international trade allow us to extend these laws to the regions of the Russian Federation [10]. 


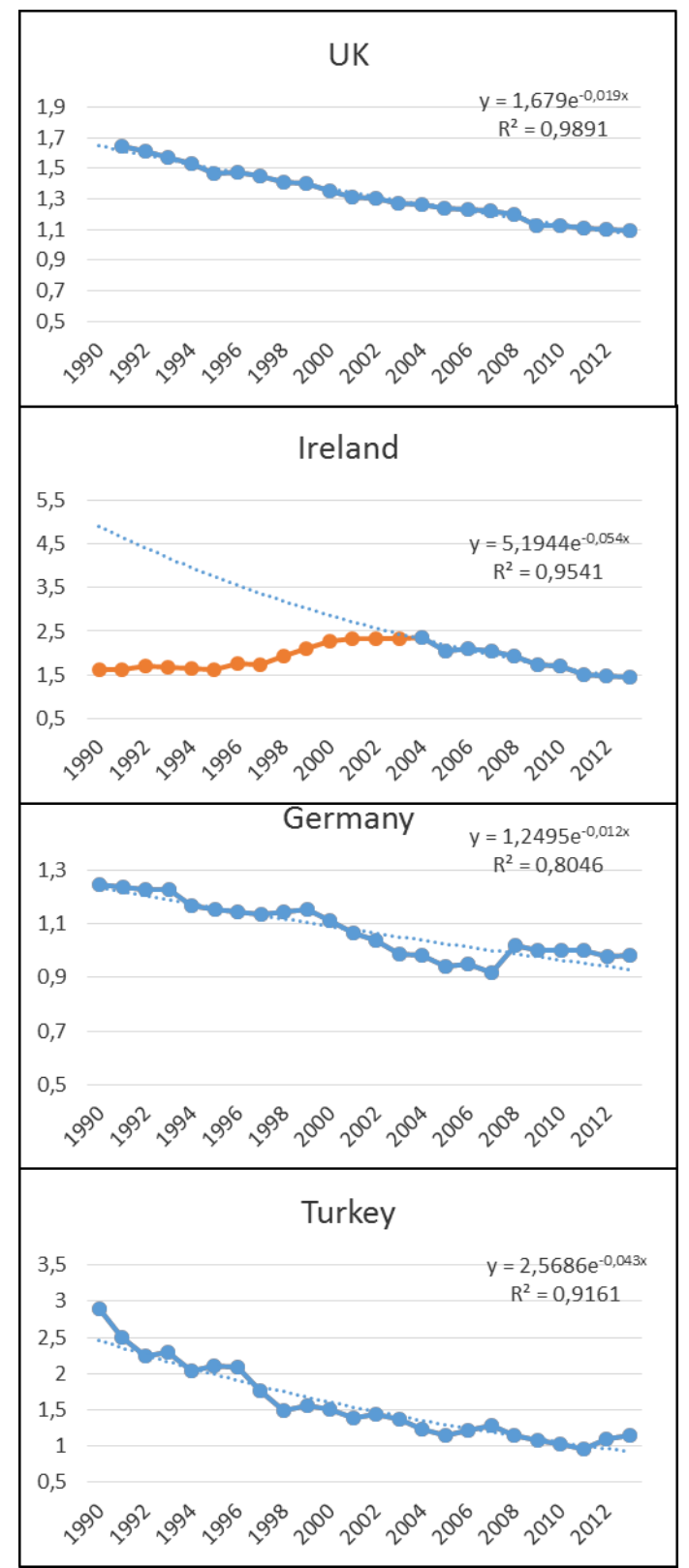

Fig 2. Dynamics of energy consumption of one vehicle in road transport, tonnes of oil equivalent per vehicle per yearSource: European Commission: Eurostat; World Bank

Most of motor vehicles are imported by Russia from Europe and Japan, which results in similarity of the energy consumption reducing processes in the transport sector, as well as European countries.

\subsection{Changing structure of the energy balance for road transport}

The role of alternative sources of energy (biofuels, natural gas, electricity) has been recently notably increasing in the transport sector, which is a limiting factor for an increase in demand for conventional fuels in the road sector - gasoline and diesel fuel $[11,12]$.

For example, over the last three decades, the share of petroleum products was characterized by a continuous decline in the energy balance of Europe in the transport sector [13]. In the period from 1990 to 2005, the share of oil products in the region decreased from 98.7 to $97.2 \%$. The period of high oil prices and the economic crisis of
2008-2009 acted as incentive to switch to more economical alternative energy sources [14]. As a result, over 5 years - from 2005 to 2010 - the share of oil products fell from $97.2 \%$ to $93.5 \%$. By 2013, the consumption of gasoline and diesel fuel accounted for 92.9\% (Table 1).

Table 1. The structure of fuel consumption in road transport in Europe, \%

\begin{tabular}{|l|c|c|c|c|c|c|c|c|}
\hline $\begin{array}{c}\text { The type } \\
\text { of energy }\end{array}$ & 1990 & 1995 & 2000 & 2005 & 2010 & 2011 & 2012 & 2013 \\
\hline Gasoline & 57,8 & 53,7 & 47,2 & 38,1 & 30,5 & 29,5 & 28,5 & 27,7 \\
\hline Diesel fuel & 40,9 & 44,9 & 51,2 & 59,0 & 63,0 & 63,6 & 64,1 & 65,2 \\
\hline Natural gas & 1,2 & 1,2 & 1,4 & 1,7 & 2,1 & 2,2 & 2,3 & 2,5 \\
\hline Biofuels & 0,0 & 0,1 & 0,2 & 1,1 & 4,4 & 4,6 & 5,0 & 4,6 \\
\hline Electricity & 0,01 & 0,01 & 0,01 & 0,01 & 0,02 & 0,02 & 0,02 & 0,03 \\
\hline
\end{tabular}

The world development in the last decade is characterized by the rapidly growing consumption of biofuels in the transport sector. So, in the period of 2005 2013 , the share of biofuels in the structure of energy consumption in Europe has increased from $1.1 \%$ to $4.6 \%$. The total transportation consumption of alternative energy sources such as natural gas, biofuels, electricity in 2013 was $7.1 \%$, whereas in 2000 their share was not greater than $1.7 \%$.

The share of diesel fuel tends to increase in the structure of energy consumption by transport is increasing rapidly. Diesel fuel is more economical in terms of fuel consumption (lower by 30-35\% versus gasoline). In addition, diesel fuel is cheaper in European countries due to lower tax rate. As a result, the use of diesel fuel as an energy carrier in the transport sector grew from $40,9 \%$ to $65.2 \%$ in the period $1990-2013$.

Despite the increase in energy efficiency and the change in the structure of energy sources in road transport, it remains the largest and fastest growing source of greenhouse gas emissions. In general, in OECD countries, transport accounts for more than $30 \%$ of greenhouse gas emissions. In the period of 2013-2016 greenhouse gas emissions by fuel combustion in cars rose by $5.9 \%$ in the countries of the European Union (Fig. 3).

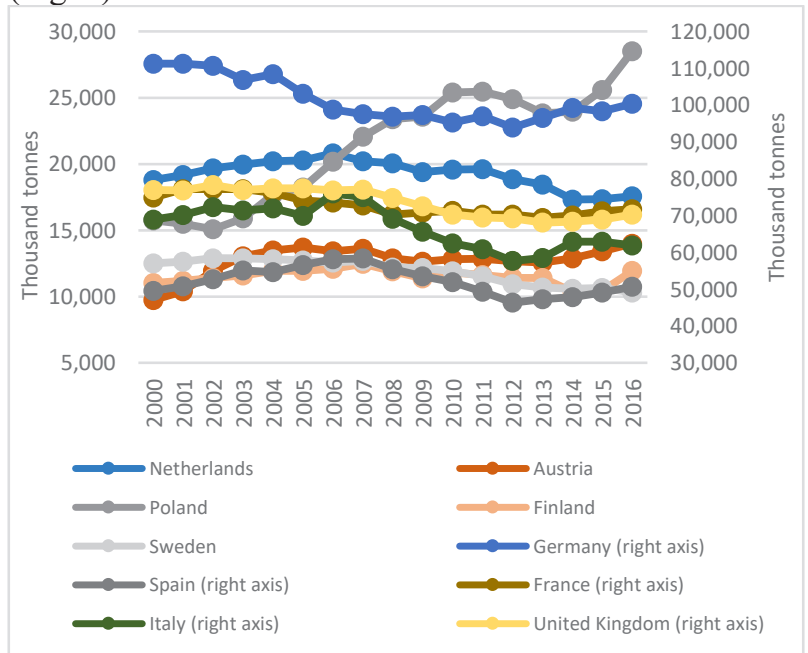

Fig 3. Greenhouse gas emissions by fuel combustion in carsSource: European Commission: Eurostat. 


\section{Methodology}

\subsection{Data}

The pattern of energy consumption dynamics for road transport in Europe was analyzed on the basis of the Eurostat data presented for 32 countries for the period 1990-2013 [9].

For the analysis of changes in energy efficiency in transport, a database has been compiled for 32 European countries on such indicators as:

- Consumption of all types of energy in road transport;

- The total number of road vehicles, including cars, buses, motorcycles, trucks and tractors.

The construction of multifactorial regression and identification of key factors affecting the population's provision with motor transport was carried out on the basis of a database formed according to World Bank statistics. The database included 18 indicators for 63 countries. The selected indicators were divided into 6 groups of factors characterizing the comparative situation of countries:

- Ecological and nature-climatic factors;

- Cost factors;

- Infrastructural factors;

- Institutional factors;

- Technological factors;

- Socio-economic factors.

When calculating the predicted values of the amount of road transport for the period up to 2040, scenario forecasts of the world population (UN Department of Economic and Social Affairs) and the GDP forecast for PPP (World Bank) were used.

\subsection{Empirical analysis}

As was shown in the paper by Eder L., Nemov V. (2016), the cumulative forecast for energy consumption of road transport per capita was calculated as multiplying of the total number of vehicles by energy consumption of a vehicle unit (1) [4]. In addition, the population projections were used to calculate the absolute number of vehicles in the regions. They are based on the optimistic scenario of population dynamics in Russia according to the UN.

$$
E_{\text {tr } i t}=\left(V_{i t}^{a}+V_{i t}^{b}+V_{i t}^{t}\right) * P_{i t} * Y_{i t}
$$

$E_{\text {tr it }}$ - energy consumption of vehicles in region $i$ at time $t ; V_{i t}^{a}-$ the number of passenger vehicles per 1000 people in region $i$ at time $t$ (calculated by authors); $V_{i t}^{b}-$ number of buses per 1000 people in region $i$ at time $t$ (calculated by author); $\mathrm{V}_{\mathrm{it}}^{\mathrm{t}}$ - the number of freight vehicles per 1000 people in region $i$ at time $t$ (calculated by author); Yit - energy consumption for one vehicle in region $\mathrm{i}$ at time $\mathrm{t}$ (calculated by authors); Pit - predicted number of population in region $i$ at time $t$ (based on the forecast of the Department of economic and social Affairs of the United Nations) [10].

\subsubsection{A model for predicting the number of vehicles}

A model for predicting the number of vehicles is based on the patterns of change in the number of vehicles per person depending on the dynamics of GDP per person. Gompertz function best describes this functionality:

$$
V_{t}=V_{\max } e^{-\alpha e^{-\beta G D P_{t}}}
$$

$\mathrm{V}_{\mathrm{t}}$ - the number of motor vehicles per 1000 people at time $\mathrm{t} ; \mathrm{V}_{\max }$ - "saturation level", desired equilibrium number of motor vehicles per 1000 people; GDP - GDP per capita in time $t ; \alpha, \beta>0$ - parameters.

To determine the specific factors that affect the "saturation level" of Vmax, a multifactor regression is constructed.

As a result of econometric analysis, the following 5 factors that have the greatest impact on the specific number of vehicles have been identified: $\mathrm{CO}_{2}$ emissions per capita $(\mathrm{E})$; percentage of urban population, \% (U); cost of diesel fuel, USD / liter (P); hours per year spent on payment of basic types of taxes $(\mathrm{H})$; density of roads, km per 1000 sq. km (R).

The regression equation has the form:

$V=-163,72+14,06 * E+2,3 * \mathrm{U}+133,83 * P-0,16 * H+0,04 * \mathrm{R}(3)$

Inclusion of these factors in the model allows for calculation of the indicator $\mathrm{V}_{\max }$ for each country, taking into account the specifics of countries: with different levels of economic development, economic structure, natural and climatic conditions, the level of development of institutions and infrastructure.

\subsubsection{The model of energy consumption by unit of the vehicle}

The model of energy consumption by a vehicle unit was based on time series analysis, with subsequent plotting the for dynamic trend model.

As shown in the previous section, the forecast values of consumption of energy in transport will be calculated on the basis of the exponential dependence:

$$
Y_{t}=\beta * \mathrm{e}^{-\gamma \mathrm{t}}
$$

$\mathrm{Y}_{\mathrm{t}}$ - energy consumption of one vehicle in year $\mathrm{t}$, o.e.; $\beta$ - energy consumption of one vehicle in the initial period (period $\mathrm{t}=0) ; \gamma-$ coefficient of the intensity reduction of energy consumption.

Calculation of parameters of the exponential function for Russian regions was carried out on the basis of obtained regularities of the effect of consumption convergence of across regions. The authors have shown the existence of the effect of beta-convergence, showing the relationship of initial level and subsequent decline in energy consumption per unit vehicle. The effect of betaconvergence allows assessing the dependence of the rate of decline of energy consumption in the region $\mathrm{i}\left(\gamma_{i}\right)$ from its initial value $\left(\beta_{i}\right)$ :

$$
\gamma_{i}=0,219 * \beta_{i}-0,126
$$


As the result, the higher is energy consumption per unit of a motor vehicle, the higher is the rate of its decline. However, when energy consumption by a motor vehicle approaches the average level of developed European countries, the rate of its decline becomes slower. To evaluate the effect of beta-convergence enables the use of trend models to predict energy consumption by road transport with a limited observation period for this indicator.

\subsubsection{Emission of greenhouse gases by road transport}

The forecast of greenhouse gas emissions is calculated on the basis of the predicted number of vehicles, the volume of demand for various types of fuel on motor vehicles and the assessment of the quality of environmental performance of road transport. The volume of greenhouse gas emissions in year $t$ is calculated by the formula:

$$
G_{t}=\sum_{j} E_{j t} * G F_{j t}
$$

Where $E_{j t}-$ the volume of demand for fuel $\mathrm{j}$ in year $\mathrm{t}$; $\mathrm{GF}_{\mathrm{jt}}$ - emission factor (specific emission of greenhouse gases per ton of burned fuel $\mathrm{j}$ in year $\mathrm{t}$ ).

The volume of demand for the fuel $\mathrm{j}$ is calculated on the basis of the forecast of the amount of road transport, specific energy consumption and changes in the structure of energy carriers. The change in the GFjt emission factor over time is calculated on the basis of the average $\mathrm{CO}_{2}$ emissions per $\mathrm{km}$ from new cars and the average life of the vehicles.

\section{Results and discussion}

\subsection{Forecast of the number of vehicles}

According to the built forecast of the number of passenger cars calculated according to the proposed model, by 2040 the growth of the number of cars by $13 \%$ is expected on the territory of Europe (Table 2).

Table 2. Forecast of the number of cars in Europe and Russia, million pieces

\begin{tabular}{|l|c|c|c|c|c|c|c|}
\hline Country & $\begin{array}{c}201 \\
5\end{array}$ & $\begin{array}{c}202 \\
0\end{array}$ & $\begin{array}{c}202 \\
5\end{array}$ & $\begin{array}{c}203 \\
0\end{array}$ & $\begin{array}{c}203 \\
5\end{array}$ & $\begin{array}{c}204 \\
0\end{array}$ & $\begin{array}{c}2040 / 2015, \\
\%\end{array}$ \\
\hline Austria & 4,7 & 4,8 & 4,9 & 5,0 & 5,1 & 5,2 & 111 \\
\hline Belgium & 5,6 & 5,8 & 5,9 & 6,0 & 6,1 & 6,1 & 110 \\
\hline $\begin{array}{l}\text { United } \\
\text { Kingdom }\end{array}$ & 29,6 & 31,0 & 32,0 & 32,8 & 33,4 & 34,0 & 115 \\
\hline Hungary & 3,2 & 3,5 & 3,6 & 3,7 & 3,8 & 4,0 & 123 \\
\hline Germany & 45,2 & 45,7 & 45,5 & 45,0 & 44,4 & 43,6 & 96 \\
\hline Greece & 5,3 & 6,3 & 7,1 & 7,6 & 7,9 & 8,1 & 154 \\
\hline Denmark & 2,4 & 2,6 & 2,7 & 2,9 & 3,0 & 3,1 & 126 \\
\hline Spain & 22,7 & 23,7 & 24,0 & 24,2 & 24,3 & 24,4 & 107 \\
\hline Italy & 37,7 & 38,8 & 39,2 & 39,4 & 39,4 & 39,4 & 104 \\
\hline Netherlands & 8,0 & 8,3 & 8,5 & 8,6 & 8,6 & 8,6 & 107 \\
\hline Norway & 2,6 & 2,8 & 2,9 & 3,0 & 3,1 & 3,2 & 124 \\
\hline Poland & 20,9 & 22,5 & 22,9 & 23,0 & 22,7 & 22,3 & 107 \\
\hline Turkey & 10,3 & 13,1 & 15,2 & 17,2 & 18,9 & 20,2 & 196 \\
\hline Finland & 3,2 & 3,3 & 3,5 & 3,7 & 3,9 & 3,9 & 123 \\
\hline France & 31,5 & 32,4 & 33,4 & 34,3 & 35,0 & 35,5 & 113 \\
\hline Sweden & 4,6 & 4,8 & 5,0 & 5,2 & 5,3 & 5,5 & 119 \\
\hline Russia & 44,3 & 50,9 & 55,4 & 57,8 & 58,8 & 59,2 & 134 \\
\hline
\end{tabular}

The largest increase in number of cars is projected in Turkey (96\%), Greece (54\%), and Denmark (26\%). In Germany, by 2020 , the positive dynamics of the number of road vehicles will be replaced by a smooth decline, which is explained by the forecasted population decline. As a result, by 2040 the number of cars will decrease by $4 \%$ compared to the level of 2015. Russia has a significant potential for increasing the number of cars. Which is mainly due to the low current level of provision of the population with motor transport. As a result, by 2040 , an increase in the number of cars by $34 \%$ is forecasted for Russia.

\subsection{Forecast of energy consumption per unit of a motor vehicle}

The calculations show that by 2040 the level of specific energy consumption in transport in Europe will be reduced by a factor of 1.5-2 (Table 3 ). In this case, there will be a significant reduction in the differentiation of this indicator among countries. As a result, the average level of energy consumption in Europe per car will be 0.75 toe.

Table 3. Forecast of energy consumption per unit of a motor vehicle, toe / vehicle

\begin{tabular}{|l|c|c|c|c|c|c|c|}
\hline \multicolumn{1}{|c|}{ Country } & 2005 & 2010 & 2015 & 2020 & 2025 & 2030 & 2040 \\
\hline Austria & 1,60 & 1,31 & 1,19 & 1,12 & 1,05 & 0,98 & 0,86 \\
\hline Belgium & 1,38 & 1,36 & 1,19 & 1,08 & 0,99 & 0,90 & 0,75 \\
\hline Cyprus & 1,36 & 1,24 & 1,07 & 0,97 & 0,89 & 0,81 & 0,67 \\
\hline Czech Republic & 1,03 & 1,00 & 0,99 & 0,91 & 0,85 & 0,79 & 0,68 \\
\hline Denmark & 1,60 & 1,55 & 1,44 & 1,34 & 1,24 & 1,15 & 0,99 \\
\hline Finland & - & 1,08 & 0,95 & 0,88 & 0,82 & 0,76 & 0,66 \\
\hline France & 1,09 & 1,02 & 0,95 & 0,89 & 0,84 & 0,78 & 0,69 \\
\hline Germany & 0,94 & 1,00 & 0,93 & 0,87 & 0,82 & 0,77 & 0,69 \\
\hline Greece & 1,15 & 0,81 & 0,73 & 0,69 & 0,65 & 0,62 & 0,55 \\
\hline Hungary & 1,12 & 1,10 & 1,10 & 1,03 & 0,97 & 0,90 & 0,79 \\
\hline Ireland & 2,05 & 1,70 & 1,46 & 1,37 & 1,29 & 1,22 & 1,08 \\
\hline Italy & 0,88 & 0,75 & 0,71 & 0,65 & 0,59 & 0,54 & 0,45 \\
\hline Netherlands & 1,27 & 1,18 & 1,14 & 1,07 & 1,01 & 0,95 & 0,84 \\
\hline Norway & 1,43 & 1,41 & 1,26 & 1,16 & 1,08 & 0,99 & 0,85 \\
\hline Poland & 0,74 & 0,77 & 0,63 & 0,61 & 0,59 & 0,57 & 0,53 \\
\hline Spain & 1,17 & 0,97 & 0,87 & 0,82 & 0,77 & 0,72 & 0,64 \\
\hline Sweden & 1,52 & 1,41 & 1,36 & 1,30 & 1,24 & 1,19 & 1,08 \\
\hline United Kingdom & 1,24 & 1,13 & 1,04 & 0,95 & 0,86 & 0,79 & 0,65 \\
\hline Russia & - & - & 1,33 & 1,24 & 1,16 & 1,08 & 0,94 \\
\hline
\end{tabular}

\subsection{Forecast of change of structure of consumption of energy in transport}

Analysis of tendencies of changes in the structure of energy consumption in transport has allowed executing the forecast for the medium term. The share of alternative sources energy (LPG, natural gas, biofuels, electricity) in road transport in 2020 will increase to $9.7 \%$, in $2040-24 \%$. In the structure of energy consumption will be a significant reduction share of gasoline to $11.4 \%$ by 2040 . The share of diesel fuel will increase up to 2027 to the level of $69.1 \%$. However, an increase in the consumption of alternative energy sources will lead to stabilization and further reduction of the share of diesel fuel to the level of $64.6 \%$ by 2040 (Table 4). 
Table 4. Forecast of the structure of energy sources in motor transport, \%

\begin{tabular}{|l|c|c|c|c|c|c|}
\hline \multicolumn{1}{|c|}{ The type of energy } & 2015 & 2020 & 2025 & 2030 & 2035 & 2040 \\
\hline $\begin{array}{l}\text { Petroleum products } \\
\text { (gasoline, diesel fuel, LPG) }\end{array}$ & 94,2 & 92,7 & 90,5 & 87,6 & 84,1 & 80,0 \\
\hline $\begin{array}{l}\text { Other (biofuels, natural gas, } \\
\text { electricity) }\end{array}$ & 5,8 & 7,3 & 9,5 & 12,4 & 15,9 & 20,0 \\
\hline
\end{tabular}

\subsection{Estimation of greenhouse gas emissions}

Based on forecasts of the amount of road transport, energy consumption and structure of energy sources, an estimation of greenhouse gas emissions from fuel combustion in road transport was carried out. Various factors have a multidirectional impact on the volume of greenhouse gas emissions. On one hand, it is the improvement of the environmental characteristics of engines, the transition to alternative energy sources; on the other hand, it is the change in the population and the growth of the vehicles number. Based on the obtained results, three groups of countries can be distinguished (Table 5).

Table 5. Forecast of greenhouse gas emissions by motor vehicles in Europe, million tons

\begin{tabular}{|l|c|c|c|c|c|c|c|c|}
\hline Country & 2010 & 2015 & 2020 & 2025 & 2030 & 2035 & 2040 & $\begin{array}{c}2040 / 2015 \\
\%\end{array}$ \\
\hline Austria & 12,8 & 13,4 & 13,3 & 12,6 & 11,9 & 11,2 & 10,4 & 77,7 \\
\hline Belgium & 15,0 & 15,2 & 14,5 & 13,5 & 12,4 & 11,5 & 10,5 & 69,2 \\
\hline $\begin{array}{l}\text { United } \\
\text { Kingdom }\end{array}$ & 70,3 & 68,9 & 67,8 & 63,6 & 59,2 & 54,9 & 50,8 & 73,7 \\
\hline Hungary & 5,9 & 5,9 & 6,1 & 5,9 & 5,6 & 5,4 & 5,1 & 85,7 \\
\hline Germany & 95,3 & 98,3 & 94,8 & 87,6 & 80,6 & 73,9 & 67,5 & 68,6 \\
\hline Greece & 10,2 & 7,6 & 8,6 & 9,0 & 9,0 & 8,8 & 8,4 & 110,2 \\
\hline Denmark & 6,7 & 6,9 & 6,9 & 6,6 & 6,4 & 6,1 & 5,8 & 84 \\
\hline Spain & 51,9 & 49,1 & 48,7 & 45,7 & 42,7 & 39,8 & 37,0 & 75,3 \\
\hline Italy & 62,4 & 62,9 & 59,7 & 54,9 & 50,2 & 45,6 & 41,4 & 65,9 \\
\hline Netherlands & 19,6 & 17,3 & 17,1 & 16,1 & 15,1 & 14,1 & 13,0 & 75,2 \\
\hline Norway & 5,6 & 5,5 & 5,4 & 5,1 & 4,9 & 4,6 & 4,3 & 78,7 \\
\hline Poland & 25,4 & 25,6 & 27,3 & 26,2 & 24,8 & 23,2 & 21,5 & 84 \\
\hline Turkey & 39,9 & 69,3 & 83,6 & 88,7 & 91,1 & 90,9 & 88,4 & 127,6 \\
\hline Finland & 11,8 & 10,4 & 10,8 & 10,6 & 10,2 & 9,7 & 9,2 & 88 \\
\hline France & 71,3 & 71,2 & 69,8 & 66,5 & 63,0 & 59,4 & 55,7 & 78,3 \\
\hline Sweden & 11,9 & 10,7 & 10,4 & 10,0 & 9,7 & 9,2 & 8,8 & 82,9 \\
\hline
\end{tabular}

The first group includes countries with a developed economy and a high level of provision of the population with motor transport. In these countries, the effect of improving the environmental characteristics of engines exceeds the effect of increasing the number of vehicles, which is expected to reduce greenhouse gas emissions by 2040. This group includes Germany, France, United Kingdom, Austria, the Netherlands and Belgium.

The second group of countries is expected to have a moderate reduction in greenhouse gas emissions. These countries have less potential to reduce emissions. This is due either to high rates of increase in number of road vehicles, or with a large share of alternative fuel at the present time. This group includes Hungary, Denmark and Poland.

For the third group of countries, further growth of greenhouse gas emissions is expected. The rapid growth in the number of road transport, as a result of both low current level of motor vehicle provision and high population growth rates, will lead to a significant increase in greenhouse gas emissions. This group include, first of all, to Turkey, where emissions are projected to increase by more than $27 \%$ by.

\subsection{Estimation of greenhouse gas emissions in Russia}

The rapid growth of greenhouse gas emissions from road transport in Russia is a result of the car boom. According to the Federal State Statistics Service, in 2010-2016 the number of passenger cars in Russia increased by $31.5 \%$, exceeding 45.2 million units in 2016. As a result, the share of transport in the total volume of emissions of pollutants into the atmosphere in Russia increased to 45.1\%. In 2017 emissions from cars in Russia exceeded 14,4 million tons, the leaders in terms of emissions are Moscow and the Moscow region. At the same time, per capita emissions in Moscow, as in St. Petersburg, are lower than the average Russian level (79 and $85 \mathrm{~kg} /$ person, respectively, versus $96 \mathrm{~kg} /$ person, on average in the country).

According to the forecast, the growth of greenhouse gas emissions from fuel combustion in road transport in Russia will continue until 2024 and reach the level of 15.4 million tons, which is $6.5 \%$ higher than the level of 2015. However, the gradual saturation of domestic demand, growth of provision of population with motor transport will lead to a reduction in demand for cars. As a result, after 2025, the reduction of greenhouse gas emissions is projected. In 2040, the volume of emissions will amount to 13.3 million tons.

Reduction of greenhouse gas emissions in the regions of Russia can be explained by various factors (Table 6).

Table 6. Forecast of greenhouse gas emissions by motor vehicles in regions of Russia*, million tons

\begin{tabular}{|l|c|c|c|c|c|c|c|c|}
\hline $\begin{array}{l}\text { Federal } \\
\text { District }\end{array}$ & 2012 & 2017 & 2020 & 2025 & 2030 & 2035 & 2040 & $\begin{array}{c}2040 / 2017 \\
, \%\end{array}$ \\
\hline Central & 3,48 & 3,79 & 4,00 & 4,06 & 3,95 & 3,75 & 3,52 & 92,8 \\
\hline Northwest & 1,25 & 1,40 & 1,48 & 1,50 & 1,47 & 1,39 & 1,31 & 93,4 \\
\hline South & 1,13 & 1,65 & 1,51 & 1,53 & 1,49 & 1,41 & 1,32 & 79,9 \\
\hline $\begin{array}{l}\text { North } \\
\text { Caucasus }\end{array}$ & 0,71 & 0,86 & 0,86 & 0,87 & 0,84 & 0,80 & 0,75 & 87,7 \\
\hline Volga & 2,40 & 2,92 & 3,17 & 3,21 & 3,13 & 2,98 & 2,80 & 96 \\
\hline Ural & 1,24 & 1,32 & 1,36 & 1,39 & 1,35 & 1,28 & 1,21 & 91,7 \\
\hline Siberian & 1,80 & 1,81 & 2,02 & 2,05 & 2,00 & 1,90 & 1,79 & 99 \\
\hline Far East & 0,68 & 0,70 & 0,76 & 0,77 & 0,74 & 0,69 & 0,63 & 89,9 \\
\hline Russia, total & 12,68 & 14,45 & 15,15 & 15,38 & 14,97 & 14,19 & 13,33 & 92,2 \\
\hline
\end{tabular}

The largest region for the volume of greenhouse gas emissions is the Central Federal District, accounting for $26.2 \%$ of emissions. Despite the intensive growth in the number of vehicles in the district, by 2040 a significant reduction in greenhouse gas emissions is expected. This is due to the relatively faster pace of renewal of the fleet with the best environmental performance in the central regions of Russia. Reduction of emissions in the Far Eastern District is explained, first of all, by a decrease in the population. The least decrease in greenhouse gas emissions is projected in the Siberian Federal District. 
As by 2040 the volume of emissions will be reduced only by $1 \%$.

\section{Conclusion}

According to the forecast, in Europe the number of cars is expected to grow by $13 \%$. The largest increase in cars is projected in Turkey (96\%), Greece (54\%), Denmark (26\%). In Germany, by 2020 , the positive dynamics of the number of road vehicles will be replaced by a smooth decline, which is due to the projected population decline. The calculations show that by 2040 the level of specific energy consumption in transport in Europe will be reduced by a factor of 1.5-2, while the share of oil products in the structure of consumed fuel on motor transport is reduced. Thus in Sweden by 2040, the share of oil products is projected to decline to $68 \%$, in Denmark to $79 \%$. On average, in 2040 the share of oil products in the structure of fuel consumption in road transport in Europe will be reduced to $80 \%$. Nevertheless, in the countries of Europe, various trends in the field of greenhouse gas emissions are expected. Most countries have a high potential for reducing greenhouse gas emissions from fuel combustion on road vehicles. However, a rapid increase in the number of vehicles and low incentives for switching to alternative fuels will lead to the conservation of greenhouse gas emissions at the current level or to their growth. In Russia, emissions from vehicles are projected to reduce by $8 \%$ by 2040 . The most progressive region is the Central Federal District, where the emission reduction is associated with the improvement of the qualitative characteristics of the motor vehicles in operation with a high rate of growth in the number of cars. However, in most of Russia's regions, emission reductions are associated with low growth rates or a decline in the population.

The research was supported by the grant No. 17-78-20218.

\section{References}

1. A.E. Kontorovich, L.V. Eder, I.V. Filimonova, M.V. Mishenin, V.Yu. Nemov, Oil industry of major historical centers of the Volga-Ural petroleum province: past, current state, and long-run prospects. Russian Geology and Geophysics, Volume 57, Issue 12,2016 .
2. A.G. Korzhubaev, I.V. Filimonova, L.V. Eder, I.A. Sokolova, Strategy of development of an oil-and-gas complex Siberia. Oil Industry, Issue 3, 2009.

3. U.Y. Arslangulov, Perspectives the global transport sector. "Energy" M .: Publishing House, 2009

4. L. V. Eder, V. Yu. Nemov, I.V. Filimonova, Prospects for Transport Energy Consumption: Methodological Approaches and Results of Forecasting. World of economics and management. Vol 16, N 1, 2016.

5. J.A. Paravantis, D.A. Georgakellos, Trends in energy consumption and carbon dioxide emissions of passenger cars and buses. Technological Forecasting and Social Change, Volume 74, Issue 5, 2007.

6. B. Liddle, S. Lung, The long-run causal relationship between transport energy consumption and GDP: Evidence from heterogeneous panel methods robust to cross-sectional dependence. Economics Letters, Vol.: 121, 2013.

7. J. Dargay, D. Gately, M. Sommer, Vehicle Ownership and Income Growth, Worldwide: 19602030. Energy Journal, Vol. 28, No. 4, 2007.

8. E.Y. Khrustalev, P.D. Ratner, Advances in technology and energy efficiency in industry and transport. The economic analysis: theory and practice, No 2, 2015.

9. L.V. Eder, Forecast of world energy consumption: methodological approaches, comparative evaluation. Mineral resources of Russia. Economics and management, No 6, 2013

10. O.V. Mazurova, Power consumption of the Russian transport on the background of global trends. Energy policy, No 3, 2010.

11. The Outlook for Energy of the world and Russia until 2040. M., ERI RAS, 2014.

12. A.F. Andreev, E.M. Karpel, Strategy of natural gas as a motor fuel in road transport. Problems of Economics and Management of oil and gas complex, No 3, 2012.

13. V.Y. Petrov, Passenger transport of the future: electric cars, hydrogen cars or traditional? Automotive industry, No 5, 2009.

14. A.V. Ivanov, Current State and trends of the world's use of natural gas as an alternative fuel on vehicles. Oil, gas and business, No 5, 2011. 